\title{
Manifestação de habilidades cognitivas em um curso de férias: a construção do conhecimento científico de acordo com a Aprendizagem baseada em Problemas
}

\author{
The manifestation of cognitive skills in a vacation course: \\ the construction of scientific knowledge according to Problem \\ based Learning
}

\author{
Antonia Ediele de Freitas Coelho ${ }^{1}$ \\ https://orcid.org/0000-0003-4715-4595 \\ João Manoel da Silva Malheiro ${ }^{2}$ \\ https://orcid.org/0000-0002-2495-7806
}

\begin{abstract}
Resumo: Esta pesquisa trata das habilidades cognitivas manifestadas por um grupo de seis professores participantes de um curso de férias ocorrido na cidade de Belém (PA), o qual utiliza metodologias que procuram incentivar a participação mais ativa dos cursistas, por meio da realização de atividades práticas fundamentadas, principalmente, na Aprendizagem Baseada em Problemas (ABP). Dessa forma, objetivamos analisar quais os níveis de habilidades cognitivas manifestados pelos professores ao resolverem um problema real, durante a realização de atividades experimentais investigativas. Procuramos ainda ponderar em relação às perguntas elaboradas pelos monitores e sua relação intrínseca com as habilidades manifestadas pelos professores. Caracterizamos esta investigação como qualitativa, na qual utilizamos recursos como diários de campo e vídeogravações, com posterior transcrição das falas dos sujeitos para a constituição da mesma. As atividades desenvolvidas neste curso aproximam-se dos objetivos apresentados pela ABP sendo perceptível, em diversos momentos, manifestação de habilidades de níveis N4 e N5 de cognição nos participantes.
\end{abstract}

Palavras-chave: Conhecimento científico. Processo cognitivo. Aprendizagem baseada em problemas. Curso de férias.

\begin{abstract}
This research deals with on the cognitive skills manifested by a group of six teachers participants in a vacation course, occurred in the city of Belém (PA), which uses methodologies that seek to encourage more active participation of its course participants, by means of the realization of practical activities grounded mainly on Problem Based Learning (PBL). Thus, we aim to analyze which cognitive skills levels manifested by teachers to solve a real problem, while conducting investigative experimental activities seeks to also ponder over the questions elaborated by the monitors and its intrinsic relationship with the skills expressed by the teachers. We characterize this research as qualitative, using features such as field diaries and video recordings, with subsequent transcription of participants' speech to its constitution. The activities developed in this course approximate the objectives presented by PBL, and is perceptible at different moments, the manifestation of skills of N4 and N5 skills levels of cognition in the participating.
\end{abstract}

Keywords: Scientific knowledge. Cognitive process. Problem based learning. Vacation course.

\footnotetext{
${ }^{1}$ Universidade Federal do Pará (UFPA), Instituto de Educação Matemáticas e Científica (IEMCI), Belém, PA, Brasil. E-mail: antonia.coelho@castanhal.ufpa.br

${ }^{2}$ UFPA, Castanhal, PA, Brasil.
} 


\section{Introdução}

Este estudo é fruto de uma dissertação, e procura sintetizar os dados obtidos com o desenvolvimento da mesma (COELHO, 2016). Dessa maneira, as observações aqui ponderadas partem da análise dos momentos de interações entre o monitor ${ }^{3}$ e um grupo de professores, percebidas durante as ocasiões de realização de atividades experimentais investigativas da XXIV edição do curso de férias, intitulado Experimentando ciências: o corpo bumano em movimento ocorrido em Belém (PA), tendo como principal suporte metodológico a Aprendizagem Baseada em Problemas, do inglês Problem Based Learning (PBL) (BARROWS; TAMBLYN, 1980; SCHMIDT, 1993), ressaltando a manifestação de habilidades cognitivas (MIRI; DAVID; ZOLLER, 2007; ZOLLER; PUSHKIN, 2007; ZOLLER; DORI; LUBEZKY, 2002;), como uma das possibilidades de se alcançar o conhecimento científico.

Destacamos que a manifestação das habilidades de cognição se caracteriza como um processo que está intimamente ligado a capacidade de o sujeito se tornar competente, isto é, de desenvolver competências cognitivas que possam ser consideradas essenciais para o desenvolvimento do intelecto (GATTI, 1997). Partimos da premissa de que, para que ocorra a manifestação e identificação de habilidades cognitivas existem três componentes essenciais que auxiliam nesse procedimento: "a resolução de problemas, o pensamento crítico e a realização de atividades práticas” (ZOLLER; PUSHKIN, 2007, p. 153, tradução nossa).

Consideramos necessário destacar que, por se tratar de um ambiente caracterizado como não formal de educação, o curso de férias demonstra algumas características peculiares desses espaços como, por exemplo, apresentar um processo de ensino e aprendizagem, no qual se aprende por meio do compartilhamento de experiências, principalmente por envolver indivíduos participantes de um mesmo grupo social, em locais com ações coletivas e cotidianas carregadas de valores e culturas próprias (GOHN, 2006).

Esses ambientes caracterizam-se ainda como sendo informais, onde existem procedimentos de interatividade intencionais que são guiados à luz das diretrizes dos próprios grupos. Em vista disto, podemos relacionar o fato de que durante o curso, todas as perguntas realizadas e as problematizações levantadas são baseadas em questionamentos elaboradas pelos participantes, ou seja, são constituídas por meio de dúvidas ou curiosidades que surgem nestas ações cotidianas, evidenciadas por Gohn (2006).

Dentre os objetivos do curso, podemos destacar alguns que são assinalados por Malheiro (2009), ao evidenciar que as experiências investigativas constituem uma das principais metodologias utilizadas durante o curso, presentes dentro da perspectiva da ABP, em que os experimentos realizados se constituem como base para que possam emergir perguntas, curiosidades e, a partir destas, manifestem-se as habilidades cognitivas.

Essas características compreendem aspectos que são essenciais para a resolução de problemas e, consequentemente, para a manifestação de habilidades cognitivas em seus

\footnotetext{
${ }^{3} \mathrm{O}$ monitor é a pessoa responsável por auxiliar os grupos tutoriais, devendo este ser conhecedor dos conteúdos que serão trabalhados, facilitador da aprendizagem, podendo sua função ser comparada a de um professor (COELHO, 2016).
} 
participantes, evidenciadas por meio das interações e discussões realizadas em cada etapa de solução dos problemas propostos que, por sua vez, compreendem aspectos que podem se relacionar diretamente aos estímulos para a manifestação e identificação de habilidades cognitivas em seus participantes (ZOLLER; DORI; LUBEZKY, 2002).

Outra característica do curso é a de estimular "principalmente nos professores a importância de metodologias como a PBL/ABE"4 (MALHEIRO, 2009, p. 37), incentivando-os a analisar suas práticas em sala de aula, bem como impulsionar o trabalho em equipe, já que além das discussões ocorridas nos grupos, existem os momentos de socializações que acontecem em forma de seminário e são abertos ao público, com exposição de suas descobertas e, consequentemente, explicação do que estava sendo estudado e analisado, aos visitantes.

Segundo Miri, David e Zoller (2007), as atividades realizadas em grupo são relevantes, pois permitem que os alunos construam novos conhecimentos com auxílio de alguém mais experiente, ou seja, permite-os partilhar e discutir as observações que estão sendo realizadas e os resultados obtidos.

A participação do professor coordenador durante a realização das atividades do curso se torna essencial, sobretudo, em ocasiões em que é necessária a ponderação sobre argumentos que estão sendo apresentados. Segundo Malheiro (2009, p. 127), “a disposição do auditório ou do auditor é muito semelhante à de um juiz que deverá avaliar os argumentos expostos antes de confirmar (ou recusar) sua aprovação acerca da argumentação". As intervenções realizadas pelo professor coordenador são capazes de auxiliar e constatar as limitações dos procedimentos experimentais realizados para confirmar ou negar uma hipótese, isto é, o coordenador é indispensável durante a realização de cada uma das etapas do evento.

A partir disso, a análise da manifestação de habilidades cognitivas, se deu por meio da apreciação dos momentos de interações da equipe de professores pesquisada com os monitores, além da socialização dos dados obtidos, haja vista que, essas ocasiões também podem ser consideradas como situações de aprendizagem, na qual cabe aos monitores e ao professor coordenador formularem diversas perguntas, frequentemente, com o intuito de tentar averiguar se as respostas dos cursistas estavam de acordo com aquilo que foi observado nas experimentações, ou caso não conseguissem solucionar o problema pudessem, ao menos, exemplificar alguns pontos de vista (MALHEIRO, 2009).

Os momentos de interações que serão posteriormente analisados referem-se às ocasiões em que, nos grupos, os monitores junto à equipe de professores discutem acerca das diferentes possibilidades de realizações das experimentações, na qual é possível perceber a manifestação de habilidades cognitivas em suas variações. Consideramos relevante destacar que as habilidades aqui identificadas e analisadas compreendem, especificamente, contextos de estudo relacionados a educação em Ciências.

\footnotetext{
${ }^{4}$ A Aprendizagem Baseada em Evidências (ABE) tornou-se um dos referenciais teóricos a ser adotado pelo curso de férias, posteriormente às suas primeiras edições.
} 


\section{Habilidades cognitivas: conceitos e características}

Para compreendermos o processo da cognição humana é necessário relacioná-la a forma como as pessoas pensam, ou seja, como elas percebem, aprendem e recordam alguma informação. Dessa maneira, podemos considerar a inteligência como estrutura organizadora da cognição (STERNBERG, 2010).

Em relação a isso, compreendemos que a manifestação de habilidades cognitivas é um processo que está intimamente ligado a procedimentos de aprendizagens, podendo ser evidenciado por meio de mudanças consideradas permanentes nos sujeitos envolvidos nessa ação. Assim, essas transformações ocorrem devido a experiências compartilhadas e adquiridas por meio das relações sociais e individuais que esses indivíduos partilharam (GATTI, 1997).

Analisando conceitualmente os termos "habilidades cognitivas", Gatti (1997) evidencia que as habilidades podem ser entendidas como capacidades que tornam o indivíduo competente, ou seja, são responsáveis por formar a estrutura essencial do que conhecemos como competência cognitiva da pessoa humana. Nesse sentido, é capaz de permitir ao sujeito "discriminar entre objetos, fatos ou estímulos, identificar e classificar conceitos, levantar/construir problemas, aplicar regras e resolver problemas" (GATTI, 1997, p. 2).

Zoller, Dori e Lubezky (2002) esclarecem que a construção de habilidades cognitivas constitui o núcleo central de um conjunto de processos de desempenho necessários para lidar com situações que envolvem problemas mais complexos e sistêmicos, considerando também o que diz respeito à resolução de problemas relacionados à sala de aula, em disciplinas específicas, bem como aqueles relacionados à vida real e sua inter-relação com o contexto.

Nessa perspectiva, a manifestação de habilidades cognitivas inclui um componente da investigação científica que envolve a concepção e implementação de estratégias de ensino que visam melhorar a aprendizagem dos estudantes, por meio da integração do pensamento crítico, resolução de problemas e a tomada de decisão (MIRI; DAVID; ZOLLER, 2007).

De acordo com os autores, para enfrentar esse desafio é necessário recomendar aos estudantes analisarem situações desconhecidas, de modo que a questão problema proposta possa ser capaz de promover um quadro de pensamento crítico e racional. A união entre o pensamento crítico e a resolução de problemas forma o que podemos considerar como um guarda-chuva que abrange níveis de pensamento, níveis de conhecimento e, concomitantemente, níveis de habilidades cognitivas (ZOLLER; PUSHKIN, 2007).

Para que ocorra a manifestação de habilidades cognitivas alguns processos são necessários, já que eles podem ser apontados como o caminho para se alcançar tais habilidades. $\mathrm{Na}$ concepção dos autores, pensamento, conhecimento e cognição estão intimamente ligados e assim, as habilidades cognitivas são manifestadas pela maneira como os alunos se tornam capazes de enfrentar situações problemáticas que são apresentadas pelos professores ${ }^{5}$, tornando a aprendizagem um fator que depende de memórias, discussões, perguntas, hipóteses e soluções (MIRI; DAVID; ZOLLER, 2007; ZOLLER; PUSHIKIN, 2007).

\footnotetext{
${ }^{5} \mathrm{O}$ termo professor nesta pesquisa pode ser substituído pela figura do monitor, que é o responsável pela condução das atividades realizadas durante o curso de férias (MALHEIRO, 2009).
} 


\section{Os níveis de habilidades cognitivas}

Algumas habilidades cognitivas são descritas e categorizadas por Zoller, Dori e Lubezky (2002) e Zoller e Pushkin (2007). Tais categorias foram classificadas como: algorítmicas (ALG); habilidades cognitivas de baixa ordem (lower order cognitive skills, LOCS); e habilidades cognitivas de alta ordem (higher order cognitive skills, HOCS).

Dessa forma, os problemas algorítmicos (ALG) podem tanto ser evidenciados como uma única categoria, quanto como uma categoria inferior à de habilidades cognitivas de baixa ordem (LOCS), sendo caracterizada por representar exposições de pensamento, na qual os alunos são levados a demonstrar ou aplicar conhecimentos algorítmicos memorizados para responder "corretamente" exercícios prontos, isto é, "uma resposta correta a uma questão bem definida" (ZOLLER; PUSHKIN, 2007, p. 153, tradução nossa).

As habilidades cognitivas de baixa ordem (LOCS) são assinaladas com o objetivo de dar ênfase a definições formais, equações, algorítmicos, que se resumem a lembrar, saber, definir e identificar fórmulas ou conceitos memorizados que podem ser aplicados unicamente em situações familiares, ou seja, envolvendo exercícios objetivos e sem problematização do que está sendo estudado (ZOLLER; PUSHKIN, 2007).

Já as habilidades cognitivas de alta ordem (HOCS) podem ser definidas como aquelas orientadas por meio de questões problemas, envolvendo a investigação, análise de variáveis, promoção das primeiras hipóteses para a resolução do problema (não exercícios), abrangendo também a construção do pensamento crítico, da tomada de decisão, pois são consideradas como problemas que não são do conhecimento dos alunos e necessitam de saberes adicionais para o seu desenvolvimento (ZOLLER; DORI; LUBEZKY, 2002).

Como demonstrado, os níveis de habilidades cognitivas são categorizados de acordo com as particularidades percebidas nas respostas elaboradas pelos alunos a uma indagação promovida pelo professor, e podem variar de baixo a alto nível de cognição. Cada uma das três categorias elencadas por Zoller, Dori e Lubezky (2002) possuem níveis de manifestação que podem ser simplificados por meio do quadro 1.

Em relação a isso, Suart (2008) considera que as respostas dadas pelos alunos possuem uma relação direta com as perguntas elaboradas pelo professor, haja vista que, verificamos que o nível cognitivo de respostas dadas pelos estudantes é definido pelo tipo de questão que é formulada pelo docente, evidenciando o papel do monitor enquanto mediador do conhecimento que será construído pelos alunos.

Baseando-nos em outras pesquisas que objetivavam analisar o nível das questões orais e escritas propostas pelo professor como, por exemplo, Malaver, Pujol e D’Alessandro Martinez (2005), Suart (2008), e Yarden, Brill e Falk (2001), elencamos algumas categorias de análise que procuram relacionar o nível das perguntas elaboradas pelo monitor com o nível de habilidades cognitivas alcançados pelos alunos, de acordo com quadro 2. 
Quadro 1 - Nível cognitivo categorizado de acordo com as respostas dos alunos

\begin{tabular}{|c|c|}
\hline Nível & Categoria de resposta ALG \\
\hline N1 & $\begin{array}{l}\text { Não reconhece a situação problema; } \\
\text { Limita-se a expor um dado relembrado; } \\
\text { Retêm-se a aplicação de fórmulas ou conceitos. }\end{array}$ \\
\hline Nível & Categoria de resposta LOCS \\
\hline N2 & $\begin{array}{l}\text { Reconhece a situação problemática e identifica o que deve ser buscado; } \\
\text { Não identifica variáveis; } \\
\text { Não estabelece processos de controle para a seleção das informações; } \\
\text { Não justifica as respostas de acordo com os conceitos exigidos. }\end{array}$ \\
\hline N3 & $\begin{array}{l}\text { Explica a resolução do problema utilizando conceitos já conhecidos ou relembrados } \\
\text { (resoluções não fundamentadas, por tentativa) e quando necessário representa o problema } \\
\text { com fórmulas ou equações; } \\
\text { Identifica e estabelece processos de controle para a seleção das informações; } \\
\text { Identifica as variáveis, podendo não compreender seus significados conceituais. }\end{array}$ \\
\hline Nível & Categoria de resposta HOCS \\
\hline N4 & $\begin{array}{l}\text { Seleciona as informações relevantes; } \\
\text { Analisa ou avalia as variáveis ou relações causais entre os elementos do problema; } \\
\text { Sugere as possíveis soluções do problema ou relações causais entre os elementos do } \\
\text { problema. } \\
\text { Exibe capacidade de elaboração de hipóteses. }\end{array}$ \\
\hline N5 & Aborda ou generaliza o problema em outros contextos ou condições iniciais. \\
\hline
\end{tabular}

Quadro 2 - Nível cognitivo categorizado de acordo com as perguntas elaboradas pelo monitor

\begin{tabular}{|l|l|}
\hline Nível & \multicolumn{1}{c|}{ Descrição } \\
\hline P1 & Requer que o estudante somente recorde uma informação partindo dos dados obtidos. \\
\hline P2 & $\begin{array}{l}\text { Requer que o estudante desenvolva atividades como sequenciar, comparar, contrastar, } \\
\text { aplicar leis e conceitos para resolução do problema. }\end{array}$ \\
\hline P3 & $\begin{array}{l}\text { Requer que o estudante utilize os dados obtidos para propor hipóteses, fazer inferências, } \\
\text { avaliar condições e generalizar. }\end{array}$ \\
\hline P4 & $\begin{array}{l}\text { Requer que o estudante possa utilizar informações de discussões anteriores para resolução } \\
\text { de um problema específico. }\end{array}$ \\
\hline
\end{tabular}

Fonte: Adaptado de Yarden, Brill e Falk (2001); Malaver, Pujol e D’Alessandro Martinez (2005) e Suart (2008).

A pesquisa de Suart (2008) apresenta três níveis de perguntas elaboradas pelo professor (P1, P2 e P3), nesta pesquisa procuramos acrescentar o nível quatro (P4), baseando-nos na investigação de Malaver, Pujol e D’Alessandro Martinez (2005).

A partir da elaboração de perguntas que permitam aos alunos alcançarem diferentes níveis de habilidades cognitivas, o monitor, como mediador do conhecimento, se tornará um questionador propondo desafios e permitindo aos alunos conduzirem sua aprendizagem por meio da participação ativa na construção de sua aprendizagem e, concomitantemente, suas habilidades cognitivas. 
Nesse sentido, é de fundamental importância que se analise as perguntas que foram elaboradas pelo monitor, pois para que ocorra a manifestação de habilidades cognitivas e essas alcancem níveis de alta ordem de cognição, torna-se necessário que o problema sugerido seja apreciável e estimulante.

\section{A Aprendizagem Baseada em Problemas (APB) no curso de férias}

A ABP resulta do processo de trabalho encaminhado para a compreensão e/ou resolução de um problema (BARROWS; TAMBLYN, 1980). Para Schmidt (1993), a ABP caracteriza-se como uma abordagem para a aprendizagem e a instrução, na qual os estudantes lidam com problemas em pequenos grupos sob a supervisão de um monitor.

Em relação a isso, Ribeiro (2008) classifica a ABP em sua essência, como sendo uma metodologia de ensino e aprendizagem colaborativa, construtivista e contextualizada, na qual a problematização ou as situações-problemas são necessárias para que se possa iniciar, direcionar e motivar a aprendizagem.

Barret (2005) assegura que o cognitivismo, o construtivismo social e o pós-modernismo também fornecem fundamentos teóricos para se compreender a ABP. Segundo este autor, o cognitivismo está presente na ABP, pois essa metodologia é capaz de ativar processos mentais por meio do acesso ao conhecimento prévio dos estudantes, permitindo conexões entre antigos e novos conceitos, utilizando-se da elaboração de relações para a construção da teoria almejada.

Além disso, a ABP é uma metodologia centrada no aluno, que procura torná-lo intelectualmente ativo, quebrando barreiras entre as disciplinas e conectando o conhecimento novo com a experiência ativa, estando ainda intimamente relacionada a manifestação de competências e habilidades cognitivas relevantes a vida cotidiana (CARON, 2004; ZOLLER; DORI; LUBEZKY, 2002).

Em relação à formação de professores, o curso de férias se constitui como um desafio a ser enfrentado por aqueles que se dispõem a participar, haja vista que, de acordo com Rosário (2005), são vários os fatores que vem contribuindo para que o espírito questionador e pesquisador que habita em cada professor esteja sendo adormecido por práticas ligadas a um modelo de educação pouco estimulante, que se instaura desde a educação básica.

Nesse aspecto, Mota e Pereira (2015) acrescentam que os adultos se envolvem melhor em ambientes de aprendizagem que compreendem vínculos entre os fatos que se quer aprender e suas experiências de vida. Com base nisso, acreditamos que na ABP esses fatores costumam ser contemplados, já que ao utilizar esta metodologia o ambiente se torna mais motivador, com maior participação dos envolvidos, e a aprendizagem ocorre de forma prática e baseada em um problema concreto.

No curso de férias, estes fatos contribuem para que os professores tenham a oportunidade de se comportar como alunos, dentro do prisma da ABP. Esta metodologia permite também que seus participantes repensem sua função enquanto professores, e ao mesmo tempo, reconsiderem o processo de aprender e ensinar, além disso, é possível evidenciar por meio das atividades realizadas, que a ideia de que o professor sabe tudo necessita ser superada (ROSÁRIO, 2005).

Podemos evidenciar ainda que no curso de férias, as atividades experimentais investigativas em busca da solução de um problema, ocorrem em pequenos grupos de cinco a seis 
participantes, de acordo com a supervisão de um monitor, que procura por meio de indagações constantes despertar o interesse dos participantes pela pesquisa científica (COELHO, 2016).

A partir disso, são elaboradas pelos próprios participantes do curso perguntas que servem de base para o desenvolvimento das atividades experimentais investigativas (CARVALHO et al., 2009), para que, por conseguinte a equipe seja capaz de elaborar e analisar hipóteses de explicação desse problema, identificando fontes de informação, adquirindo novos conhecimentos reelaborando suas ideias iniciais, afim de corroborarem com as informações alcançadas (VASCONCELOS; ALMEIDA, 2012).

É válido ressaltar que, a cada dia é selecionado um participante da equipe para ficar responsável por anotar todas as ponderações e recomendações que são sugeridas para tentar solucionar o problema proposto, além disso, cabe a este participante a função de escrever um relatório sucinto das atividades realizadas, pois durante os momentos de socialização é feita a exposição das descobertas realizadas e, a esse participante, dá-se a denominação de secretário (MALHEIRO, 2009).

\section{Trama metodológica da pesquisa}

Para alcançar os objetivos propostos com essa pesquisa, perpassamos por caminhos que podem determiná-la dentro da abordagem qualitativa, já que procuramos explicar o porquê dos acontecimentos analisados, evidenciando características reais do ambiente investigado, e um desenvolvimento cercado de fatos imprevisíveis, centrando-se na compreensão e explicação da dinâmica das relações sociais (GERGHART; SILVEIRA, 2009).

De acordo com Bogdan e Biklen (1994), a pesquisa qualitativa é também descritiva, o que justifica a escolha da utilização de vídeogravações, com posteriores transcrições das falas dos participantes e monitores do curso de férias, ressaltando que cada diálogo foi transcrito na íntegra, sem aboná-los, modificar suas ordens, ou quaisquer tipos de alterações que pudessem substituir seus objetivos.

Nesse sentido, optamos por analisar as transcrições com base na análise microgenética, que na perspectiva de Werstch (1988, p. 26, tradução nossa) "se refere a formação a curto prazo de um processo psicológico determinado”. A análise desse tipo de domínio, requer a observação das repetidas tentativas dos sujeitos em tentar solucionar uma determinada tarefa e, podemos dizer que esse tipo de análise é um estudo intenso (por ser minucioso) e a curto prazo (por representarem análise meticulosa de episódios breves) (GÓES, 2000; WERSTCH, 1988).

O curso analisado teve duração de uma semana, sendo necessário destacar que foram ressaltados nesta investigação somente os episódios referentes ao segundo, terceiro e quarto dia de curso, por serem os momentos considerados cruciais para a manifestação das habilidades cognitivas, em virtude de terem ocorridos logo após o primeiro momento de socialização das atividades realizadas, e culminarem com a apresentação do segundo seminário.

Nesta pesquisa, a duração dos episódios considerados corrobora com as ideias apresentadas por Góes (2000), quando a autora afirma que não parece existir um critério específico para determinar sua duração, no entanto, optamos por episódios curtos, pois assim se tem a oportunidade de analisá-los de forma mais cautelosa. 
Dessa maneira, os episódios foram divididos em momentos que oportunizaram discussões diretivas, nas quais um problema foi apresentado e discutido, demonstrando as fases de sua realização, com a apresentação de resultados que puderam confirmar (ou não) as hipóteses levantadas inicialmente pelos professores participantes.

Resumidamente, podemos evidenciar que essa investigação é micro por ser orientada para minúcias indiciais, que facilmente passam despercebidas no cotidiano de uma sala de aula, e é genética por buscar relacionar esses eventos simples àqueles pertinentes a história e sociogénetica, que envolvem o processo de desenvolvimento social e cognitivo (GÓES, 2000).

Baseando-nos nesses pressupostos teórico-metodológicos, essa investigação se fundamentou por meio da análise e compreensão de como se deu o processo de manifestação e identificação das habilidades cognitivas expostas por um grupo de seis professores participantes de um curso de férias. Sendo assim, as habilidades cognitivas manifestadas pelos professores foram analisadas de acordo com sua relação intrínseca às perguntas realizadas pelos monitores.

Nesta edição do curso tivemos a participação de 38 alunos, entre estudantes de pósgraduação, graduação e da educação básica (Ensino Médio) e 14 professores, totalizando 52 cursistas. Os sujeitos selecionados foram seis professores da rede pública de ensino que, no papel de alunos, deveriam encontrar-se em um ambiente (quase que) completamente diferente do que estavam acostumados, enfrentando os desafios, dificuldades e também habilidades que os estudantes vivenciam continuamente em sala de aula, já que um dos objetivos do curso é "buscar alternativas viáveis que permitam a preparação do professor para enfrentar os novos desafios decorrentes da explosão de conhecimentos científicos” (MALHEIRO, 2009, p. 35-36).

O grupo de professores analisados eram atuantes nas áreas de Química e Física, e quatro desses em Biologia, todos têm em comum o fato de trabalharem em uma Escola Estadual de Ensino Médio no município de Belém, embora alguns deles também se dediquem a outros colégios da cidade.

Os participantes foram identificados pela letra sílaba Part seguidos por um número que os diferencie ( 1 a 6 ) de acordo com a identificação proposta pelos autores. Já as falas dos monitores foram identificadas pelas letras $M n$, seguidos da identificação Mn1 e Mn2 para caracterizar os dois monitores responsáveis pelas atividades realizadas pela equipe.

\section{Análise e identificação das habilidades cognitivas manifestadas pelos cursistas}

Com a formação dos grupos, os momentos de interações da equipe de professores com seus respectivos monitores deram-se a princípio, sobretudo, pelo surgimento de várias ideias que iam se firmando por meio de perguntas, exemplos, dúvidas, enfim, por uma "chuva de ideias" que, com o auxílio dos monitores acabaram se afunilando em uma única questão que serviu de base para a construção do conhecimento científico e de habilidades cognitivas (COELHO, 2016).

A partir disso, os professores discutiram com os monitores as diversas possibilidades de pesquisas que poderiam ser realizadas envolvendo o corpo humano e que estivessem ligadas as suas áreas de atuação. No entanto, era comum que por vezes os monitores pedissem ao grupo de professores, que esquecessem os conteúdos trabalhados nas escolas com os alunos, da forma 
mecânica como isso era apreendido por eles, e discutido com os estudantes. $\mathrm{O}$ foco do curso era o de aprimorar esses conhecimentos, mas de forma contextualizada, por meio da resolução de problemas e, principalmente, envolvendo a anatomia comparada (MALHEIRO, 2009).

Dessa forma, destacamos a primeira problemática, que consistia em descobrir se existe uma conexão entre o cérebro e as demais partes do corpo. Essa questão surgiu a partir da Part1, quando ela comentou que ao participar de um curso, assistiu um vídeo no qual um paciente com aneurisma submeteu-se a uma cirurgia em que seria introduzido um cateter pelo braço, e a partir daí, chegaria ao cérebro e lá cauterizaria o aneurisma.

Podemos evidenciar que "essa etapa inicial deverá motivar e direcionar os alunos a observar aquela situação de aprendizagem de acordo com seus próprios valores, crenças ou conhecimentos", ou seja, este é o momento de apresentar suas ideias, opiniões, e ao monitor cabe a função de direcionar "a atenção dos alunos para aquele problema específico" (DECKER; BOUHUIJS, 2009, p. 195).

Como todos os professores do grupo ficaram curiosos com essa problemática, evidenciaram umas das principais características da utilização da ABP no curso de férias (VASCONCELOS; ALMEIDA, 2012), que consistiu no momento em que os participantes definiram o problema que buscaram resolver com base em um procedimento experimental. Nessa perspectiva, o grupo de professores, sujeitos de nossa pesquisa, elaborou a seguinte pergunta: "existe algum tipo de ligação entre o cérebro e as demais partes do corpo?".

Além desse questionamento, outros surgiram ao longo das atividades com o objetivo de complementar a essa problemática inicial como, por exemplo: “O coração bombeia sangue para o cérebro e todo o resto do corpo?” e "Qual das cavidades do coração é responsável por bombear a maior quantidade de sangue?" No entanto, essas perguntas não compreendem os objetivos dessa investigação.

\section{Situação problemática I: Análise morfológica do coração e sua ligação com as demais partes do corpo}

Para tentar solucionar essa pergunta inicial, o grupo organizou em uma sala alguns materiais para análise, dentre eles, um camundongo formolizado, bem como peças anatômicas do coração humano (disponibilizadas do acervo do curso de medicina da Universidade Federal do Pará, UFPA) que foram utilizados para subsidiar com mais precisão o desenho experimental planejado, objetivando fundamentar com base na experimentação investigativa, suas respostas à questão elaborada. Primeiramente, optaram por analisar visualmente o animal em solução de formol, discutindo as possibilidades de manuseio e experimentos que poderiam ser realizados.

O grupo discutiu previamente com um dos monitores as etapas para a realização dos experimentos. Durante esse momento, foi notória a dificuldade dos professores em externalizarem somente os pontos evidenciados através do experimento planejado/executado e que pudesse ser utilizado claramente em suas análises. Contudo, a presença do professor coordenador com indicações de como eles poderiam realizar suas investigações, foi essencial para que as características do curso pudessem ser postas em evidência, ou seja, o professor coordenador os auxiliou no sentindo de impulsioná-los a ressaltar em suas observações, principalmente, características daquilo que estivesse sendo observado. $O$ foco do curso era o de aprimorar esses conhecimentos, mas de forma contextualizada, por meio da resolução de problemas e, especialmente, envolvendo a anatomia comparada (MALHEIRO, 2009). 
É importante destacar que todas as atividades envolvendo a manipulação de camundongos vivos durante esta e as demais edições do curso de férias foram aprovadas pelo Comitê de Ética em Pesquisa com Animais de Experimentação (CEPAE) e autorizada também por meio do Parecer Bio 052-12 (COELHO, 2016). Assim, o episódio transcrito no quadro 3 procura demonstrar como se deu esse momento de interação entre professores e monitores.

Quadro 3 - Ensaio experimental: existe algum tipo de ligação entre o cérebro e as demais partes do corpo?

\begin{tabular}{|c|c|c|}
\hline Turno & Discurso & Análise \\
\hline 01 & $\begin{array}{l}\text { Mn2: Tá inflando? Coloca mais devagar, tá inflando aí também [Referindo-se ao pulmão } \\
\text { formolizado de um camundongo]. }\end{array}$ & P1 \\
\hline 02 & $\begin{array}{l}\text { Part2. Tá indo pro... pro pulmão. Ôpa, ôpa, a gente tinha que ter abrido [sic] aqui ob, } \\
\text { aberto. }\end{array}$ & N1 \\
\hline 03 & Mn2. Para, para um pouco! & \\
\hline 04 & $\begin{array}{l}\text { Part2. Aqui ôh, tá ficando verde aqui [Apontando para o abdômen do camundongo]. } \\
\text { Acho que ela tá presa lá com superbonder, mas ela ficou 'dançando' lá dentro. }\end{array}$ & N1 \\
\hline 05 & Mn2. Abre tudo. & \\
\hline 06 & Part6. Não é que tá rápido, é que tá mudando rápido. & N1 \\
\hline 07 & $\begin{array}{l}\text { Mn1. Isso é uma hipótese, você não pode dizer que tá rápido demais se você não sabe a } \\
\text { velocidade. Mas pode ser que esteja rápido demais. E aí varou a cavidade do coração? Vai } \\
\text { devagar. }\end{array}$ & P3 \\
\hline 08 & $\begin{array}{l}\text { Part2. Vocês estão vendo aqui que tá ficando verde no figado? Vocês conseguem ver? Aqui a } \\
\text { gente não sabe dizer se é que tá vazando do coração ou se é o que tá colorido o vaso, mas eu } \\
\text { acho que é porque tá colorindo o vaso sim por dentro. Então a extremidade superior, anota } \\
\text { aí, apresentou coloração e o fígado, as extremidades superiores também, coloca aí, primeiro foi } \\
\text { o fígado, eu tô vendo umas coisinhas verdes aqui dentro do fígado e ai as patas superiores, aí } \\
\text { agora ele tá comę̧ando a apresentar coloração na parte inferior e rabo. Olha as extremidades } \\
\text { da cabeça também já estão apresentando coloração verde. }\end{array}$ & N3 \\
\hline
\end{tabular}

Fonte: elaborado pelos autores a partir de dados da pesquisa.

Podemos observar que os professores realizaram os experimentos com bastante cautela e contaram com o auxílio constante dos monitores, como observamos nos turnos 01 e 03. Nos turnos 04 e 06, os professores Part2 e Part6, respectivamente, apresentaram níveis de habilidades caracterizadas com nível N1 de cognição, já que nesse início do experimento limitaram-se a expor somente o que conseguiram visualizar, se retendo a dados empíricos e sem demonstrar o reconhecimento da situação problema (ZOLLER; PUSHKIN, 2007).

Com a continuação da discussão, a Mn1 realizou uma pergunta caracterizada com nível P3, pois elaborou um questionamento que não se limitou a uma resposta fechada, oportunizando aos professores ponderarem sobre as possíveis hipóteses do que estava sendo observado, como podemos perceber no turno 07 (SUART, 2008).

As intervenções propostas pela monitora, ainda em relação a este turno, demonstraram com exatidão o quanto sua presença foi fundamental durante esse momento, uma vez que 
Mn1 propôs intervenções elucidativas que direcionaram para que os professores pudessem se basear e problematizar os resultados, além de solicitar aos participantes a elaboração adicional de suas ideias.

Tal fato pode ser evidenciado na resposta concebida pela Part2, em que ela incidiu sobre o problema proposto pela Mn1 e criou suas próprias ponderações acerca do que foi observado, como vemos no turno 08 "[...] aqui a gente não sabe diz̧er se é que tá vazando do coração ou se é o que tá colorido o vaso, mas eu acho que é porque tá colorindo o vaso sim por dentro [...]".

Esse argumento da Part2, por sua vez, assinalou o nível N4 de habilidade cognitiva, já que nesse momento a professora selecionou as informações que julgou mais relevantes, analisando os dados obtidos empiricamente e sugerindo cabíveis soluções para o problema (ZOLLER; DORI; LUBEZKY, 2002).

O episódio ainda é capaz de destacar o quanto todas as etapas utilizadas para a realização das atividades experimentais investigativas foram imprescindíveis, destacando desde as observações minuciosas até a coleta dos dados. Porém, ressaltamos que as hipóteses precisaram ser destacadas da mesma maneira que os procedimentos, pois rever com maior cautela o que está sendo realizado requer prudência e rigorosidade, já que esses foram os fatores essenciais para que se efetivasse a análise e interpretação dos dados obtidos (CARVALHO et al., 2009).

Em geral, os monitores davam algumas pistas ou caminhos a serem seguidos e, dessa forma, a realização de experimentações investigativas almejava que seus participantes, fossem eles alunos ou professores, pudessem ressignificar "os conteúdos didáticos trabalhados nos experimentos, no sentido de, aos poucos, irem constatando que a Ciência lança mão de uma linguagem própria para descrever suas teorias" (MALHEIRO, 2009, p. 144).

Dessa maneira, suas proximidades com a ABP tornavam-se mais evidentes, haja vista que, as atividades além de acontecerem em grupos, o curso "era centrado quase que exclusivamente nos participantes [...], no qual todos os partícipes trabalhavam de forma colaborativa no laboratório (ou fora dele)" (MALHEIRO, 2009, p. 198).

Segundo Rosário (2005) durante a realização das atividades experimentais investigativas, os professores têm a oportunidade de repensarem suas práticas, pois nesta ocasião revivem suas experiências como alunos, sentindo a necessidade de questionar, de solicitar auxílio e ver na figura do monitor suporte para dar continuidade a busca por respostas as suas indagações.

Mota e Pereira (2015), complementam esta ideia, considerando que todo o processo de desenvolvimento intelectual humano necessita ser estimulante para os envolvidos e, assim, requer tanto a valorização de sua visão de mundo quanto o planejamento das ações que serão desenvolvidas.

Assim, concluímos esse primeiro momento de verificação dos dados obtidos a partir dos resultados iniciais alcançados, no entanto, ele apresenta continuidade que se deu por meio da recordação do que havia sido realizado. Para isso, o secretário responsável por registrar tudo que foi alcançado, relembrou-os algumas das informações que já haviam sido observadas, como vemos no episódio do Quadro 4. 
Manifestação de habilidades cognitivas em um curso de férias: ...

Quadro 4 - Continuação do ensaio experimental: existe algum tipo de ligação entre o cérebro e as demais partes do corpo?

\begin{tabular}{|l|l|l|}
\hline Turno & \multicolumn{1}{|c|}{ Discurso } & Análise \\
\hline 09 & Mn1. Por que vocês acham que foi primeiro a superior? & $\mathrm{P} 3$ \\
\hline 10 & Part2. Eu acho que é por causa do cérebro. & $\mathrm{N} 4$ \\
\hline 11 & Mn1. Será que é por causa da proximidade? & $\mathrm{P} 4$ \\
\hline 12 & Part1. Os vasos... vai ver que os vasos estão no caminho primeiro pra cima. & $\mathrm{N} 4$ \\
\hline 13 & Mn1. Primeiro pra cima? E depois vai pra baixo? & $\mathrm{P} 4$ \\
\hline 14 & $\begin{array}{l}\text { Part2. Eu acho que têm pra cima e pra baixo, só que como tá mais perto em cima chega } \\
\text { primeiro pra cima do que pra baixo [Referindo-se aos vasos]. }\end{array}$ & $\mathrm{N} 5$ \\
\hline 15 & Mn1. Isso é uma hipótese [...] & $\mathrm{P} 1$ \\
\hline 16 & Mn2. E aí foi pro pulmão ainda? & $\mathrm{N} 2$ \\
\hline 17 & Part6. Pro pulmão só quando eu fiz muito rápido. & $\mathrm{P} 3$ \\
\hline 18 & Mn2. Pois é... se tu fizer muito forte, vai estourar muita coisa lá dentro? & $\mathrm{N} 3$ \\
\hline 19 & $\begin{array}{l}\text { Part3. Tu estavas fazendo na mesma velocidade da salina, não é na mesma velocidade da } \\
\text { salina. }\end{array}$ & $\mathrm{N} 5$ \\
\hline 20 & $\begin{array}{l}\text { Part2. Se nós tivéssemos determinado um padrão de adição a gente poderia dizer 'em tal } \\
\text { velocidade a pressão enche o pulmão'. }\end{array}$ & $\mathrm{P} 4$ \\
\hline 21 & Mn1. Vocês conseguiram resolver o que estava em aberto? & $\mathrm{N} 5$ \\
\hline 22 & $\begin{array}{l}\text { Part2. Vamos lá... existe um caminho pra circulação? Sim, existe. Pra onde vai esse } \\
\text { caminho? Pra cima e pra baixo. Por que a gente concluiu isso? Porque a gente demonstrou } \\
\text { através de experimento que o verde foi pra cima e pra baixo e a gente ainda demonstrou que o } \\
\text { corante verde ele corou primeiro a parte superior e depois a parte inferior. }\end{array}$ & \\
\hline
\end{tabular}

Fonte: elaborado pelos autores a partir de dados da pesquisa.

Inicialmente, no turno 09 a pergunta realizada pela monitora salientou uma discussão riquíssima que evidenciou um progresso na manifestação de habilidades cognitivas da equipe de professores. Elaborando uma pergunta de nível P3, a Mn1 conseguiu fazer com que os professores realizassem inferências àquilo que estava sendo pesquisado, associando os dados empíricos de suas descobertas ao que lhes parecia mais plausível, admitindo avaliações sobre os resultados obtidos (MALAVER; PUJOL; D’ALESSANDRO MARTINEZ, 2005; SUART, 2008), o que os levou a associarem suas descobertas ao problema inicial, como aconteceu no turno 10 "Eu acho que épor causa do cérebro", evidenciando uma resposta de nível N4 de cognição, com a evidente elaboração de hipóteses.

Lipman (1995, p. 132) corrobora com esta ideia ao afirmar que as habilidades cognitivas ou habilidades de pensamento de alta ordem estão associadas ao pensar que é "experimental, probatório, provisório, exploratório e questionador”, haja vista que esses são alguns requisitos necessários para lidarmos com situações que são problemáticas.

Podemos perceber que, ao obter uma resposta satisfatória dos professores, a Mn1 continua a interrogá-los com uma pergunta P4 no turno 11, permitindo que esse "pensamento questionador" seja capaz de desenvolver o "pensamento exploratório" do grupo de docentes, 
já que ao explorarem as proposições sugeridas pela equipe e as indicadas pela monitora, notavelmente ampliaram-se as habilidades cognitivas dos professores (LIPMAN, 1995).

Prosseguindo o experimento, a Mn1 permaneceu com um "pensamento questionador" de nível P4 no turno 12, o que auxiliou consideravelmente a Part2 alcançar o nível mais alto de habilidades cognitivas, na perspectiva de Zoller, Dori e Lubezky (2002), pois neste momento a professora conseguiu abordar o problema em outro contexto, ou seja, passou a considerar que a proximidade com o cérebro influencia na direção e caminho que é realizado pelo sangue dentro dos vasos, demonstrando o nível N5 de cognição.

A partir desse episódio conseguimos identificar uma gradativa evolução nas habilidades cognitivas manifestadas pelo grupo de professores, uma vez que, as perguntas preparadas pelos monitores contribuíram significativamente para que as respostas elaboradas alcançassem os níveis de alta ordem de cognição.

Nesse sentido, as informações acarretadas, por exemplo, no turno 20 em que a Part2 procurou debater outra possível variante para os resultados obtidos, afirmando que "se nós tivéssemos determinado um padrão de adição a gente poderia dizer 'tal velocidade a pressão enche o pulmão", evidenciou claramente o nível N5 de cognição, pois com isso passou-se a considerar que a velocidade de injeção do líquido poderia influenciar no local para onde este seria guiado pelo coração (ZOLLER; PUSHKIN, 2007; ZOLLER; DORI; LUBEZKY, 2002).

Dessa forma, Gatti (1997) afirma que a manifestação de habilidades cognitivas também pode ser evidenciada por meio de descobertas, reconhecimentos ou pelas redescobertas, sendo estas bem mais influenciadas pela motivação do que pela habilidade propriamente dita, isto é, considerando que o desenvolvimento dos seres humanos consiste nas relações que são construídas, no contato com o outro, faz sentido aproximar as habilidades cognitivas às representações, percepções e expectativas das pessoas.

Podemos considerar que as habilidades cognitivas não surgem única e exclusivamente dos professores participantes, mas apresentaram-se como uma construção que se deu por intermédio da relação com o monitor, da motivação que por eles foi imposta ao grupo, por meio das perguntas elaboradas de acordo com cada discussão proposta (GATTI, 1997).

Outro fato a ser considerado é que o progressivo aumento na manifestação das habilidades cognitivas alcançou os mais altos níveis de cognição, conforme os participantes buscaram apoiar suas respostas nas evidências experimentais problematizando os resultados, como aconteceu neste episódio (quadro 4).

Após a concretização dos experimentos, as equipes realizaram o segundo seminário, no qual alguns erros cometidos nos primeiros experimentos foram sanados e as observações minuciosas desses ensaios experimentais foram realizadas com mais cautela, para que as respostas obtidas não se resumissem aos conhecimentos teóricos já trazidos pelos professores, mas fossem capazes de aproximarem-se das evidências experimentais. Como podemos observar no quadro 5 . 
Manifestação de habilidades cognitivas em um curso de férias: ...

Quadro 5 - Momento de socialização dos resultados obtidos

\begin{tabular}{|l|l|l|}
\hline Turno & Discurso & Análise \\
\hline 23 & $\begin{array}{l}\text { Part3. Nós repetíamos, porque erramos né, porque foi pra tal experimento, já que nós } \\
\text { aplicamos no coração do lado esquerdo... porque foi pro pulmão e não pro resto do corpo, a } \\
\text { hipótese seria que nós realmente tínhamos injetado tanto [...] que tinha passado pro lado } \\
\text { direito. Ai essa foi uma confirmação e a gente foi verificar [...], como nós injetamos esse líquido. } \\
\text { E aí foi que nós podemos observar tudo isso, que nossos colegas vão descrever aí. }\end{array}$ & N4 \\
\hline 24 & $\begin{array}{l}\text { Part2. Nossos resultados, nós demonstramos que quando inserimos o líquido no experimento, } \\
\text { olíquido esverdeado, nós demonstramos que existe uma circulação que leva do coração até todo } \\
\text { o corpo e essa circulação ela parte do lado esquerdo do coração e existe outra circulação que } \\
\text { ela vai... que vai só do coração pro pulmão, a gente inseriu um escalpe do lado direito, com } \\
\text { outra cor e esse corante foi só pro pulmão, nós conseguimos visualizar os vasos, a gente fez uma } \\
\text { dissecação dos membros superiores e inferiores demonstrando que nós conseguimos visualizar os } \\
\text { vasos, nós vimos como que é a circulação e a circulação ocorre nos vasos. }\end{array}$ & N5 \\
\hline Fonte: elaborado pelos autores a partir de dados da pesquisa.
\end{tabular}

No turno 23 obtivemos uma resposta elaborada do problema proposto inicialmente. Neste turno, Part3 procurou simplificar os dados obtidos com os experimentos, expondo em seu discurso habilidade de nível N4 de cognição, considerando que foi explicado o que e como foi realizado o procedimento experimental.

Em razão disso, a Part2 conseguiu descrever como foi realizada a atividade na prática, contando que ao inserir um escalpe com líquido colorido do lado esquerdo do coração, esse se espalhou por todo o corpo, e ao inseri-lo no lado direito direcionou-se ao pulmão, ocorrendo todo esse procedimento por meio de vasos, o que caracterizou uma abordagem do problema em outras circunstâncias, evidenciando o nível N5 de cognição.

Durante esse mesmo turno, Part2 conseguiu ainda responder à pergunta inicial do grupo, já que os experimentos evidenciaram que "[...] existe uma circulação que leva do coração até todo o corpo [...]", ou seja, os dados, as informações e as descobertas não se resumiram somente aos conhecimentos teóricos dos professores, as evidências passaram a ganhar mais destaque a partir desse momento, o que pode justificar o aumento considerável do nível de habilidades cognitivas alcançadas pelos participantes.

Com a apresentação do segundo seminário, podemos evidenciar a ascensão das habilidades, pois no episódio experimental que deu início às análises (quadro 3), percebemos que o grupo de professores ainda estava em dúvidas a respeito dos resultados que estavam observando, e sobre como poderiam justificar os dados obtidos com base em suas averiguações. Assim, demonstraram inicialmente níveis de habilidades cognitivas de baixa ordem, porém, conseguiram alcançar habilidades de alta ordem, durante o momento de socialização.

\section{As habilidades que se destacaram na XXIV edição do curso de férias}

As interações percebidas e evidenciadas nesta edição do curso ganham ênfase ao considerarmos esse processo como essencial para a manifestação de habilidades de cognição. As relações entre cursista-cursista e cursista-monitor foram de grande relevância para que cada nível de habilidade pudesse ser manifestado pelo grupo de professores considerados. 
Analisando cada um dos episódios que se constituem como um todo dentro do contexto da situação problemática proposta e desenvolvida pelos professores, podemos destacar que as diversas intervenções dos monitores em forma de questionamento ou intervenções, foram cruciais para que os professores demonstrassem a construção do conhecimento científico.

Ponderando sobre cada um dos episódios destacados, observamos que a manifestação das habilidades cognitivas segue um padrão de progresso, e é influenciado pela forma como as perguntas são elaboradas pelos monitores, como o fluxograma 01 procura sintetizar:

Figura 1 - Fluxograma de padrão de manifestação das habilidades cognitivas

\begin{tabular}{|c|c|}
\hline Pergunta de nível P1 & Habilidades Cognitivas de nível N1 \\
\hline Perguntas de nível P2 & Habilidades Cognitivas de nível N2 \\
\hline Perguntas de nível P3 & $\cdot$ Habilidades Cognitivas de nível N3 \\
\hline Perguntas de nível P4 & $\cdot$ Habilidades Cognitivas de nível N4 \\
\hline
\end{tabular}

Fonte: elaborada pelos autores.

Esse modelo procura demonstrar a principal influência para o progresso das habilidades de cognição dentro do curso, que são as perguntas realizadas pelos monitores, porém, a ordem dessa manifestação não ocorre de maneira padronizada, isso quer dizer que dependendo de como os participantes estão desenvolvendo seus experimentos ou quaisquer atividades propostas, as perguntas alteram seus níveis e, consequentemente, as respostas também.

\section{Considerações finais}

Esta pesquisa investigou as habilidades cognitivas manifestadas por um grupo de seis professores ao participarem de um curso de férias. Os resultados da análise evidenciaram que, a utilização de atividades experimentais investigativas, contribuíram significativamente para o manifestação e evidência de habilidades que variaram de baixa a alta ordem de cognição.

Nessa perspectiva, as perguntas realizadas pelos monitores demonstraram grande relevância, em razão de que, conforme as indagações caracterizavam níveis mais altos de complexidade, os níveis de habilidades de cognição evidenciados também aumentavam. Esse padrão de manifestação e identificação da relação grau de dificuldade das perguntas e níveis de habilidades cognitivas pôde ser observado em todos os episódios analisados.

As atividades práticas desenvolvidas nesse curso de férias aproximam-se dos objetivos da ABP, já que seus pressupostos estabelecem um ensino dinâmico no qual os próprios professores participantes puderam desenvolver competências em diversificados campos do conhecimento, levando em consideração que estes tinham diferentes áreas de formação, permitindo 
aos professores a possibilidade de elaborarem e testarem as etapas que devem ser consideradas como base para a ação investigativa e a resolução de um problema real.

Dessa forma, o cumprimento dessas etapas forneceu os subsídios necessários para proporcionar aos professores participantes a manifestação de habilidades cognitivas, colaborando com a construção do conhecimento científico.

Neste sentido, podemos concluir que, o curso de férias contribuiu expressivamente para a manifestação de habilidades cognitivas de alta ordem em seus participantes, sendo evidenciado por meio do grupo de professores analisados. Destacando diversos momentos em que se demonstraram habilidades de nível N4 e N5, nos quais os professores apresentaram a capacidade de elaboração de hipóteses e de generalização do problema a outros contextos, não se limitando aos dados apresentados durante as discussões levantadas, demonstrando, assim, os mais altos níveis de cognição.

Ciente das limitações encontradas dentro do ambiente investigado, que por ter uma curta duração e apresentar como principal metodologia de suas atividades a ABP, que ainda é pouco difundida dentro dos ambientes formais de ensino e, portanto, apresenta-se como uma novidade aos cursistas, consideramos possível presumir a ânsia por investigações que possam analisar a manifestação de habilidades cognitivas em consonância com a construção do conhecimento científico nos mais diversificados ambientes de ensino e aprendizagem.

\section{Referências}

BARRETT, T. Understanding problem-based learning. In: T. BARRETT, T.; MACLABHRAIM, I.; FALLON, H. (org.). Handbook of enquiry and problem-based learning: Irish case studies and international perspectives. Galway: AISHE, 2005. p. 13-25.

BARROWS, H.; TAMBLY, R. Problem-based learning: an approach to medical education. Dordrecht: Springer, 1980.

BOGDAN, R.; BIKLEN, S. Investigação qualitativa em educação: uma introdução à teoria e aos métodos. Porto: Porto Editora, 1994.

CARON, C. R. Aprendizagem problematizada no ensino médico na perspectiva do construtivismo piagetiano. 2004. 107 f. Dissertação (Mestrado em Educação) Universidade Federal do Paraná, Curitiba, 2004.

CARVALHO, A. M. P.; VANNUCCHI, A. I.; BARROS, M. A.; GONÇALVES, M. E. R.; REY, R. C. Ciências no ensino fundamental: o conhecimento físico. São Paulo: Scipione, 2009.

COELHO, A. E. F. O desenvolvimento de habilidades cognitivas em um curso de

férias: a construção do conhecimento científico de acordo com a aprendizagem baseada em problemas. 2016. 101 f. Dissertação (Mestrado em Educação em Ciências) - Universidade Federal do Pará, Belém, 2016. 
DECKER, I. R.; BOUHUIJS, P. A. J. Aprendizagem baseada em problemas e metodologia da problematização: identificando e analisando continuidades e descontinuidades nos processos de ensino-aprendizagem. In: ARAÚJO, U. F.; SASTRE, G. (org.). Aprendizagem baseada em problemas no ensino superior. São Paulo: Summus, 2009. p. 177-204.

GATTI, B. A. Habilidades cognitivas e competências sociais. Santiago de Chile: OREALC, 1997.

GERGHART, T. E.; SILVEIRA, D. T. Métodos da pesquisa. Porto Alegre: Editora da UFRGS, 2009.

GÓES, M. C. R. A abordagem microgenética na matriz histórico cultural. Cadernos CEDES, Campinas, v. 20, n. 50, p. 9-25, 2000.

GOHN, M. G. Educação não-formal, participação da sociedade civil e estruturas colegiadas nas escolas. Ensaio: avaliação e políticas públicas em educação, Rio de Janeiro, v. 14, n. 50, p. 27-38, 2006.

LIPMAN, M. O pensar na educação. Petrópolis: Vozes, 1995.

MALAVER, M.; PUJOL, R.; D’ALESSANDRO MARTINEZ, A. Análisis de actividades y preguntas propuestas sobre el tema de la estructura de la materia en textos universitarios de química general. Investigación Educativa, México, v. 16, n. 1, p. 93-98, 2005.

MALHEIRO, J. M. S. A resolução de problemas por intermédio de atividades experimentais investigativas relacionadas à biologia: uma análise das ações vivenciadas em um curso de férias em Oriximiná (PA). 2009. Tese (Doutorado em Educação para a Ciência) - Universidade Estadual Paulista Júlio de Mesquita Filho, Bauru, 2009.

MIRI, B.; DAVID, B.-C.; ZOLLER, U. Purposely teaching for the promotion of higher-order thinking skills: a case of critical thinking. Research in Science Education, Dordrecht, v. 37, n. 4, p. 353-369, 2007.

MOTA, M. S. G.; PEREIRA, F. E. L. Desenvolvimento e aprendizagem: processo de construção do conhecimento e desenvolvimento mental do indivíduo. [2015]. Disponível em: http://portal.mec.gov.br/setec/arquivos/pdf3/tcc_desenvolvimento.pdf. Acesso: 2 jul. 2018.

RIBEIRO, L. R. C. Aprendizagem baseada em problemas (PBL): uma experiência no ensino superior. São Carlos: EdUFScar, 2008.

ROSÁRIO, D. G. Formação de professores: a aprendizagem baseada em problemas e sua contribuição para o desempenho do professor na sala de aula. 2005. 167 f. Dissertação (Mestrado em Educação em Ciências) - Universidade Federal do Pará, Belém, 2005.

SCHMIDT, H. G. Problem-based learning: rationale and description. Medical Education, Chichester, v. 17, n. 2, p. 11-16, 1993.

STERnBERG, R. J. Psicologia cognitiva. 5. ed. São Paulo: Cengage Learning, 2010.

SUART, R. C. Habilidades cognitivas manifestadas por alunos do ensino médio de química em atividades experimentais investigativas. 2008. Dissertação (Mestrado em Ensino de Ciências) - Universidade de São Paulo, São Paulo, 2008. 
TEIXEIRA, J. F. Mente, cérebro \& cognição. 4. ed. Petrópolis: Vozes, 2000.

VASCONCELOS, C.; ALMEIDA, A. A aprendizagem baseada na resolução de problemas no ensino das ciências: propostas de trabalho para ciências naturais, biologia e geologia. Porto: Porto Editora, 2012.

WERSTCH, J. V. Vygotsky y la formación social de la mente. Barcelona: Paidós, 1988.

YARDEN, A.; BRILL, G.; FALK, H. Primary literature as a basis for a high-school biology curriculum. Journal of Biological Education, New York, v. 35, n. 4, p. 190-195, 2001.

ZOLLER, U.; PUSHKIN, D. Matching higher-order cognitive skills (HOCS) promotion goals with problem-based laboratory practice in a freshman organic chemistry course. Chemistry Education Research and Practice, Ioannina, v. 8, n. 2, p. 153-171, 2007.

ZOLLER, U.; DORI, Y.; LUBEZKY, A. Algorithmic and LOCS and HOCS (chemistry) exam questions: perfomance and attitudes of college students. International Journal of Science Education, Abingdon, v. 24, n. 2, p. 185-203, 2002.

Artigo recebido em 18/07/2017. Aceito em 22/10/2018.

Contato: Universidade Federal do Pará, Instituto de Educação Matemáticas e Científica, Rua Augusto Corrêa, 01, Belém PA, 66075110, Brasil. 
